\title{
CAMPUH KODE RING LELAMPAHAN "SIDAKARYA" TOPENG BONDRES INOVATIF SANGGAR SENI NONG-NONG KLING
}

\author{
Gd. Edy Putra Udayana ${ }^{1}$, I. B. Rai ${ }^{1}$, I. B. Putra Manik Aryana ${ }^{2}$ \\ Jurusan Pendidikan Bahasa Bali \\ Universitas Pendidikan Ganesha \\ Singaraja, Indonesia \\ e-mail: \{edyputra424@gmail.com, bagus.rai@undiksha.ac.id, \\ yc9cda@yahoo.com\}@undiksha.ac.id
}

\begin{abstract}
KUUB
Tetilikan puniki matetujon nelatarang (1) soroh campuh kode sajeroning lelampahan "Sidakarya" topeng bondres inovatif sanggar seni nong-nong kling, (2) soroh campuh kode manut pawiwit basa sajeroning lelampahan "Sidakarya" topeng bondres inovatif, (3) kahanan campuh kode sajeroning lelampahan "sidakarya" topeng bondres inovatif. Sane dados jejering tetilikan inggih punika lelampahan "sidakarya" topeng bondres inovatif sanggar seni nong-nong kling Panandang tetilikan inggih punika campuh kode. Palihan tetilikan sane kaanggen inggih punika deskritif kualitatif. Kramaning tetilikan sane kaanggen sakadi dokumentasi lan sadu wicara. Data tureksa sane kaanggen minakadi mastikayang data, reduksi data, nyorohang data lan panyutetan. Pikolih tetilikan sakadi, (1) soroh campuh kode manut wit basanyane, sakadi campuh kode ka tengah, campuh kode ka sisi, campuh kode cecampuhan, (2) soroh campuh kode manut wangun kerta basanyane minakadi wangun kruna, frase, lan klausa, (3) kahanan campuh kode, minakadi pendidikan, pergaulan, teknologi.
\end{abstract}

Kruna Jajaton: campuh kode, topeng bondres, sanggar seni nong-nong kling.

\begin{abstract}
ABSTRAK
Penelitian ini bertujuan menjelaskan (1) jenis campur kode dalam pementasan "sidakarya" topeng bondres inovatif sanggar seni nong-nong kling, (2) jenis campur kode berdasarkan asal bahasa dalam pementasan "sidakarya" topeng bondres inovatif, (3) faktor yang menyebabkan campur kode dalam pementasan "sidakarya" topeng bondres inovatif. Subjek penelitian adalah pementasan "sidakarya" topeng bondres inovatif sanggar seni nong-nong kling. Objek penelitian adalah campur kode. Rancangan penelitian yang digunakan adalah deskritif kualitatif. Metode penelitian yang digunakan adalah metode dokumentasi dan wawancara. Analisis data yang digunakan seperti identifikasi data, reduksi data, klasifikasi data, dan kesimpulan. Hasil penelitian yaitu, (1) jenis campur kode berdasarkan asal bahasanya, seperti campur kode ke dalam, campur kode ke luar, campur kode campuran. (2) jenis campur kode berdasarkan bentuk bahasanya seperti bentuk kata, frase, dan klausa. (3) faktor yang menyebabkan campur kode, seperti pendidikan, pergaulan, teknologi.
\end{abstract}

Kata Kunci: campur kode, topeng bondres, sanggar seni nong-nong kling. 


\section{ABSTRACT}

The aim of this research is to explain (1) the kind of mix code in the show of innovative topeng bondres "sidakarya" by nong-nong kling art studio, (2) the kind of mix code is based from the origin language in the show of innovative topeng bondres "sidakarya", (3) the factor that caused mix code in the show of innovative topeng bondres "sidakarya". The subject of this research is the show of innovative topeng bondres "sidakarya" by nong-nong kling art studio. The object of this research is the mix code. The research design used was descriptive qualitative. The methods that used for this research are documentatioan and interview. The data analysis that used such as data identification, data reduction, data classification, and summary. The results of this research are (1) the kind of mix code based on its language, like inner mix code, outer mix code, mixed mix code, (2) the kind of mix code based on its language form such as words form, phrase, and clause, (3) the factor that caused mix code, such as education, association, technology.

Keyword: mix code, topeng bondres, nong-nong kling. 


\section{PURWAKA}

Topeng inggih punika dramatari tradisional sane banget kasenengin olih krama Bali (Kodi, 2006). Lianan punika kahuripan miwah panglimbaknyane, topeng punika sampun akeh wenten ring kabupaten lan kota utaminyane ring Bali. Topeng punika silih tunggil seni sesolahan sane dados kasolahang ring makudangkudang upacara panca yadnya lan dados kasolahang anggen seni hiburan. Ngantos mangkin sesolahan topeng ring desa utawi kota kasub lan akeh ngrauhang krama sane nonton. Saking kawentenan punika prasida kacutetang topeng kari kasenengin olih krama Bali.

Ngenenin indik topeng, wenten soroh-soroh topeng minakadi topeng pajegan, topeng panca, lan topeng prembon. Sadurung punika, para krama sampun nguningin tetiga soroh dramatari topeng minakadi :

Topeng pajegan inggih punika dramatari topeng Bali sane dados kasengguh topeng Kuna ring Bali lan sampun wenten ngawit abad XVI (14601550) sadaweg pamerintah Raja Waturenggong ring Bali. (Bandem lan Rembang, 1976:11), Maosang indik sesolahan topeng puniki kasolahang asiki pragina topeng, makasami watek-watek topeng kasolahang olih siki pragina. Yening nglaksanayang pauwahan watek, pragina nglaksanayang pauwahan topeng lan payasan ring duur (gelungan).

Topeng panca taler dramatari topeng Bali sane kasengguh topeng Kuna ring Bali lan kawentenannyane sesampune topeng pajegan, inggih punika ngawit pamerintahan Raja Waturenggong ring Bali (Bandem lan Rembang, 1976:15). Yening maosang indik sesolahannyane topeng puniki dados kasolahang olih papat utawi lelima pragina sane sampun kepah antuk watek- wateknyane, malianan sareng topeng pajegan, ring topeng panca sampun kakepah wenten sane dados penasar kelihan, wenten sane dados penasar cerikan, wenten sane dados dalem, wenten sane dados dukuh, taler wenten sane dados bondres miwah sane lianan.

Topeng prembon inggih punika dramatari topeng Bali sane marupa cecampuhan saking makudang-kudang pahan topeng, arja, lan tarian-tarian klasik ring Bali, sakadi tari baris lan jauk. Kawentenan topeng prembon punika ngawit warsa 1942 antuk kolaborasi olih para seniman Gianyar lan Badung (Bandem lan Rembang, 1976:15-16). Punika taler wenten tiga jana sane kacutetang pinaka pangawit topeng prembon inggih punika I Nyoman Kaler sane ngangganin kota Badung, lan I Wayan Geria, I Mada Kredek sane ngangganin kota Gianyar. Ring topeng prembon taler wenten pahan-pahan yening jagi nyolahang, silih tunggil wenten sane dados penasar keliahan, wenten sane dados penasar cenikan, wenten sane dados dalem, wenten sane dados dukuh, wenten sane dados bondres miwah sane lianan.

Ring warsa 1980 wenten medal topeng bondres. Kawentenan dramatari topeng ngutamayang sesolahan bondres. Kabaos topeng bondres riantukan wenten tigang paletan sesolahan inggih punika, a) Topeng bondres punika sesolahan sane nenten nganggen reruntutan nganutin uger-uger, b) Topeng bondres punika sesolahan sane nenten nganggen reruntutan uger-uger genah lan galah, c) Topeng bondres taler sesoalahan seni sane sampun kasub. Panglimbak ring aab mangkin, topeng punike dados kasengguh pahan sane pinih anyar.

Cutetnyane sesolahan topeng bondres ring Bali dados kapah antuk 
papat ceciren sesolahan (1) Topeng pajegan, (2) Topeng panca, (3) Topeng prembon, lan (4) Topeng bondres. Ceciren sesolahan topeng sane sampun kabaos, punika kasengguh soroh-soroh sane mautama ring tatamian Budaya Bali, ngantos mangkin kari kerasayang luih mautama ring kauripan krama Hindu Bali. Wenten kalih sane dahat mautama sane dados ceciren sesolahan topeng inggih punika sane kapartama, kasenian punika kasolahang olih pragina-pragina sane nganggen topeng, taler sane kaping kalih watek sane kasolahang punika carita sane wenten ring sejarah Bali inggih punika (Babad) (Bandem, 1983).

Maosang indik basa Bali lan Topeng bondres punika mapaiketan. Ring pariindikan seni miwah budaya, topeng punika sarana nglestariang basa Bali riantukan basa punika wantah pahan saking budaya (Koentjaraninggrat, 1967). Silih tunggil seni sane sareng nglestariang basa Bali inggih punika seni topeng bondres. Akeh krama Bali sane uning tur seneng ring kesenian bondres punika riantukan kesenian inucap mapaiketan ring basa, dresta, budaya, miwah parikrama agama ring Bali. Topeng bondres puniki prasida dados srana sane mawiguna sajeroning nguningayang sakancan piteket-piteket kauripan manut budaya miwah agama.

Pinaka silih tunggil sarana nglestariang basa Bali, seni topeng bondres sane mangkin sayan kalimbakang mangda prasida nyarengin panglimbak jagat. Sane dumun, Topeng wantah pahan saking seni baBali, nanging antuk panglimbak jagat sane mangkin, bondres sampun dados seni balih-balihan. Pinaka seni balih-balihan, Topeng bondres nenten kantun kasolahang ring wewidangan pura pinaka pangiring upacara agama, nanging kasolahang ring genah-genah pakraman pinaka panglila cita. Topeng Bondres nenten prasida kapalasang ring bebanyolannyane, ngawinang krama Bali seneng miarsayang.

Bebanyolan-bebanyolan sane kapanggihin ring topeng bondres ketah kaambil saking kasujatian kauripan krama Bali sarahina-rahina. Bebanyolan punika nganggen basa sane dangan karesepang, nglilayang manah, miwah madaging piteket-piteket indik agama miwah kawentenan pamargin kauripan sane anyar. Sakancan piteket-piteket kauripan miwah agama kauningayang antuk bebanyolan indik kasujatian-kasujatian sane wenten ring krama Bali. Yening krama Bali sampun seneng miarsayang topeng bondres, pastika nenten budaya Bali kemanten sane lestari, nanging basa Bali taler sareng lestari.

Sane mangkin, akeh kapanggihin basa sane kaanggen ring topeng bondres nenten samian nganggen basa Bali. Antuk kawentenan jagat sane kabaos aor tan pawates, akeh kapanggihin kruna-kruna saking dura Bali sajeroning bebaosan topeng bondres punika. Akeh kosa basa Indonesia miwah basa Inggris sane kaanggen mabaos antuk pragina topeng bondres. Kosa basa saking basa Indonesia miwah basa Inggris sane sering kapiarsayang ring topeng bondres marupa kosa basa sane lumbrah kaanggen tur kauningin antuk krama Bali, sakadi kruna masak, biar, perlu, naik, praktis, canggih, yang penting, cantik, miwah sane lianan.

Kosa basa sane mawit saking basa dura Bali, nanging wenten ring bebaosan krama Bali sane marupa lengkara basa Bali punika kabaos campuh kode (Suhardi, 2009). Ketahnyane, campuh kode punika medal riantukan parisolah sang sane mabaos, sakadi wewidangan pakraman, kawagedan mabasa, miwah pangrasa maagama. Lianan ring punika, karumaketan sang sane mabaos, genah miwah galah (situası) informal, miwah katunaan basa 
utawi nenten wentennyane basa sane manut kaanggen, dados pariindikan sane prasida ngamedalang campuh kode (Nababan, 1991).

Campuh kode wantah silih tunggil kawentenan penyimpangan basa sane sampun ngranjing tur nglimbak ring kahuripan krama Bali. Campuh kode puniki madue iusan sane prasida ngawinang kawentenan basa Bali pinaka basa lbu sayan ical. Siosan ring punika sane mangkin sampun akeh kapanggih basa Bali kagentosin antuk basa-basa sane dangan katrima olih jadma Bali. Sakadi sane kapanggih ring bebaosan, jadma Bali sane mangkin sayan ngakehang nganggen basa Indonesia santukan sampun keni ius panglimbak.

Sakadi sane sampun katelatarang ring ajeng, akeh bebaosan topeng bondres sane madaging basa lianan ring basa Bali. Indike punika nyihnayang kawentenan campuh kode ring topeng bondres. Yening indike ring ajang nglantur mamargi sakadi punika, pastika topeng bondres nenten prasida nglestariang basa Bali riantukan akeh kruna-kruna riang basa Bali ical tur kagentosin antuk krunakruna sane kaambil saking basa dura Bali. Antuk kawentenan punika, patut kalaksanayang tetilikan nganutin indik campuh kode ring topeng bondres. Tetilikan sane kalaksanayang pacang nilikin silih tunggil topeng bondres inovatif Lelampahan "Sidakarya". Topeng bondres inovatif Lelampahan "Sidakarya" punika kasolahang antuk Sanggar Seni NongNong Kling Banyuning Tengah Singaraja ring kalangan Ayodya Arda Candra, Taman Budaya Bali.

Topeng bondres inovatif sane mamurda Lelampahan "Sidakarya" kapilih riantukan sujatinnyane punika marupa babondresan, inggih punika paletan lelampahan sane ngutamayang babanyolan (Yudabakti miwah Watra, 2007). Topeng bondres inovatif janten mapaiketan ring pariindikan sane wau medal utawi anyar. Reragragan pragina topeng bondres ngawigunayang seni topeng saking kawigunan topeng pinaka seni beBali dados seni balih-balihan pinaka silih sinunggil pariindikan anyar sane medal ring topeng bondres raris prasida kabaos inovatif (Kardji, 2007). Ketahnyane, topeng bondres nglampahang satua nganggen basa sane dangan miwah sane maosang indik kawentenan kauripan krama Bali sane sedeng anyar, sakadi ring topeng bondres puniki nyritayang indik krama Bali sane jagi ngaturang ayah ring pura Besakih.

Pragina topeng bondres inovatif Lelampahan "Sidakarya" punika nglampahang satua antuk basa Bali sane dangan karesepang antuk sang sane miarsayang taler wenten kruna-kruna basa Indonesia miwah basa Inggris sane kapanggihin ring bebaosannyane. Punika taler bebanyolan-bebanyolannyane anyar miwah prasida nglimurang manah sang sane miarsayang. Lianan ring punika, reragragan pragina-pragina topeng bondres sajeroning nglampahang satua antuk kawagedannyane mabebaosan prasida ngamedalang bebanyolanbebanyolan anggen nguningayang piteket sane sampun pastika mabuat ring kauripan sang sane miarsayang.

Maduluran antuk panelataran sakadi ring ajang, tetilik punika ngunggahang indik campuh kode ring Lelampahan "Sidakarya" Topeng Bondres Inovatif Sanggar Seni Nong-Nong Kling. Tetilikan puniki nelatarang indik soroh miwah dadalan campuh kode ring Lelampahan "Sidakarya" Topeng Bondres Inovatif Sanggar Seni Nong-Nong Kling.

Tetujon Tetilikan (1) Nelatarang soroh campuh kode sane wenten ring Lelampahan "Sidakarya" Topeng Bondres Inovatif Sanggar Seni Nong-Nong Kling. (2) Nelatarang wangun campuh kode sane wenten ring Lelampahan "Sidakarya" Topeng Bondres Inovatif Sanggar Seni 
Nong-Nong Kling. (3) Nelatarang sane ngawinang kawentenan campuh kode sajeroning Lelampahan "Sidakarya" Topeng Bondres Inovatif Sanggar Seni Nong-Nong Kling?

$\mathrm{Ri}$ sajeroning puniki pastika kaaptiang madue kawigunan majeng ring iraga sareng sami. Punika mawinan, tetilikan puniki madue kawigunan pamucuk miwah kawigunan panglimbak. Kalih kawigunan punika pacang katelatarang sakadi ring sor.

Kawigunan pamucuk inggih punika kawigunan sane prasida ngicenin pangresep indik pangweruh sane kabahbahang ring tetilikan. Tetilikan punika kaaptiang prasida ngicenin kawigunan majeng ring panglimbak pangweruh, utamanyane ngicenin gatragatra sane mapaiketan ring campuh kode sajeroning basa Bali. Kawigunan panglimbak inggih punika kawigunan sane sayuakti prasida kaanggen muputang pikobet. Ring tetilikan puniki madue tigang kawigunan panglimbak sakadi ring sor. (a) Majeng ring pangwacen. Tetilikan puniki kaaptiang prasida ngaturang paweweh indik pangweruh campuh kode sane wenten ring Lelampahan "Sidakarya" Topeng Bondres Inovatif Sanggar Seni Nong-Nong Kling. (b) Majeng ring pragina topeng bondres. Tetilikan puniki prasida kaanggen mikayunin indik basa campuh kode sane kaanggen ritatkala nglampahang topeng bondres. (c) Majeng ring panilik lianan. Tetilikan puniki dados pinaka panyanding ritatkala ngaryanin tetilikan sane asoroh. (d) Majeng ring Mahasisia. Pikolih saking tetilikan puniki prasida kadadosang sarana anggen ngwewehin kaweruhan lan prasida ngwantu para mahasisia nguningin tur ngresepang indik campuh kode ring Lelampahan "Sidakarya" Topeng Bondres Inovatif Sanggar Seni Nong-Nong Kling. (e) Majeng ring panilik. Tetilikan puniki prasida kaanggen pengalaman langsung sajeroning nguningin Lelampahan "Sidakarya" Topeng Bondres Inovatif Sanggar Seni Nong-Nong Kling.

\section{KRAMANING TETILIK}

Palihan tetilikan inggih punika tata cara ngincikang tetilikan mangda prasida ngamolihang data sane patut tur manut ring tetujon tetilikan (Wendra, 2011). Tetilikan punika wantah tetilikan deskritif kualitatif riantukan matetujon nelatarang soroh campuh kode, wangun campuh kode miwah kahanan campuh kode ring Lelampahan "Sidakarya" Topeng Bondres Inovatif Sanggar Seni Nong-Nong Kling.

Jejering tetilikan inggih punika jadma, piranti, utawi genah data variabal miwah indik sane kadadosang pikobet ring tetilikan (Arikunto, 2006). Ring tetilikan punika sane dados jejering tetilikan inggih punika ring Lelampahan "Sidakarya" Topeng Bondres Inovatif Sanggar Seni Nong-Nong Kling sane kasolahang antuk Sanggar Seni Nong-Nong Kling Banyuning Tengah Singaraja sane marupa video. Video ring Lelampahan "Sidakarya" Topeng Bondres Inovatif Sanggar Seni Nong-Nong Kling pinaka jejering tetilikan sane kaanggen ngrereh data indik soroh campuh kode miwah wangun campuh kode. Samaliha, pragina Lelampahan "Sidakarya" Topeng Bondres Inovatif Sanggar Seni Nong-Nong Kling taler dados jejering tetilikan riantukan irika genah data indik kahanan campuh kode.

Parikrama mupulang data sane kaanggen ring tetilikan puniki inggih punika kramaning dokumentasi. Sane kaping untat data tureksa sane kaanggen sajeroning tetilikan puniki inggih punika reduksi data, nyorohang data, pangwedar data, miwah panyutetan.

\section{PIKOLIH MIWAH TETEPASAN}

Tetepasan puniki mahbahang indik pikolih sane mabuat sajeroning tetilikan sane mapaiketan ring bantang pikobet miwah tetujon tetilikan. Tetepasan sajeroning tetilikan puniki marupa (1) Soroh campuh kode sane wenten ring Lelampahan "Sidakarya" Topeng Bondres Inovatif Sanggar Seni Nong-Nong Kling, (2) Wangun campuh kode sane wenten ring Lelampahan "Sidakarya" Topeng Bondres Inovatif Sanggar Seni NongNong Kling, miwah (3) Sane ngawinang kawentenan campuh kode sajeroning Lelampahan "Sidakarya" Topeng Bondres Inovatif Sanggar Seni Nong-Nong Kling.

Saking tetilikan sane sampun kamargiang, manut pawiwit basa sane 
kaambil Data campuh kode kapolihang ring Lelampahan "Sidakarya" Topeng Bondres Inovatif Sanggar Seni NongNong Kling akehnyane 233 data campuh kode, sane marupa 220 data campuh kode ka tengah, 12 data sane marupa campuh kode ka sisi miwah 1 data sane marupa campuh kode cecampuhan. Nganinin indik data campuh kode manut pawiwit basa sane kaambil. Campuh kode ka tengah sane wenten ring Lelampahan "Sidakarya" Topeng Bondres Inovatif Sanggar Seni Nong-Nong Kling minakadi 1) ljazah ring lengkara 'yen suba iraga malajah sinah ngelah ljazah', 2) bahaya ring lengkara 'mon ragane kene-kene bahayaba', 3) penafsiran ring lengkara 'salah penafsiran punika to'.

Sajeroning soroh campuh kode manut pawiwit basa sane kaambil, campuh kode ka tengah pinih akeh kapolihang. Kawentenan indike punika nyihnayang pragina bondres waged sajeroning nganggen kalih basa inucap, inggih punika basa Bali miwah basa Indonesia. Kawagedan krama Bali nganggen kalih basa punika sane kabaos nglaksanayang kedwibahasaan (Nababan, 1991). Pinaka krama Bali, pragina bondres patut uning tur waged mabasa Bali riantukan basa Bali wantah basa dasar sane kaplajahin saking alit. Lianan ring punika, pinaka krama Indonesia, pragina bondres taler patut waged tur uning mabasa Indonesia riantukan basa Indonesia wantah basa kaping kalih sane patut kauningin.

Samaliha, campuh kode ka sisi sane wenten ring Lelampahan "Sidakarya" Topeng Bondres Inovatif Sanggar Seni Nong-Nong Kling minakadi 1) toilet ring lengkara 'masi ke toilet tolalit-tolalit polll', 2) breakfast in the morning ring lengkara 'icang lakar breakfast in the morning malu', 3) update ring lengkara 'icang lakar update'.

Kawentenan campuh kode ka sisi ring Lelampahan "Sidakarya" Topeng Bondres Inovatif Sanggar Seni NongNong Kling kapolihang akidik. Samian basa pawiwit campuh kode ka sisi ring Lelampahan "Sidakarya" Topeng Bondres Inovatif Sanggar Seni Nong-Nong Kling inucap mawit saking basa Inggris. Basa
Bali miwah basa Inggris madue soroh basa sane malianan. Basa Bali ngranjing ring soroh basa Austronesia, samaliha basa Inggris ngranjing ring soroh basa Indo-Eropa (Mahsun, 2010). Indike punika anut sareng panampen (Jandra, 1991) sane maosang campuh kode ka sisi inggih punika campuh kode sane ngranjingang basa sane nenten asoroh.

Akidiknyane data campuh kode ka sisi sane kapolihang, nyihnayang kawagedan mabasa Inggris pragina bondres inucap. Basa Inggris akidik kaanggen sajeroning mabebaosan sarahina antuk pragina bondres inucap. Sajeroning data campuh kode ka sisi sane kapolihang, basa Inggris sane ngranjing pinaka campuh kode wantah basa sane sering kaanggen miwah kapiarsayang sajeroning bebaosan ring pakraman, sakadi Toilet, minimal, tip wetris

Miwah ring campuh kode cecampuhan sane wenten ring Lelampahan "Sidakarya" Topeng Bondres Inovatif Sanggar Seni Nong-Nong Kling minakadi 1) Luwak white coffee ring lengkara 'Sangkala ada luwak white coffee'.

Saking tetilikan sane kamargiang, kapolihang data campuh kode cecampuhan. Sakadi sane sampun katelatarang ring ajeng, basa sane ngarnjing pinaka campuh kode wantah basa Indonesia miwah basa Inggris. Basa Indonesia pinih akeh kakantenang, nanging basa Inggris kawentenannyane akidik pisan. Akidiknyane basa Inggris pinaka campuh kode ka sisi sane wenten ring Lelampahan "Sidakarya" Topeng Bondres Inovatif Sanggar Seni NongNong Kling, nyihnayang pragina bondres akidik ngamedalang kosa basa sane nenten asoroh. Sujatinnyane, pragina inucap prasida ngamedalang campuh kode cecampuhan riantukan pragina bondres ring Lelampahan "Sidakarya" Topeng Bondres Inovatif Sanggar Seni Nong-Nong Kling uning tur waged mabasa sane nenten asoroh, nanging ring bebaosannyane nenten kekantenang nyampuhang kalih utawi langkung soroh basa sane mabinayan. Riantukan wenten bebaosan pragina bondres sane nyampuhang kalih utawi langkung soroh 
basa, dadosnyane kapolihang campuh kode cecampuhan ring Lelampahan "Sidakarya" Topeng Bondres Inovatif Sanggar Seni Nong-Nong Kling.

Sajeroning campuh kode manut ring kerta basanyane, data sane kapolihang 205 data, 115 data ngranjing ring soroh campuh kode sajeroning wangun kruna, 58 data ngranjing ring soroh campuh kode sajeroning wangun frase, miwah 32 data ngranjing ring soroh campuh kode sajeroning wangun klausa. Campuh kode sajeroning wangun kruna sane wenten ring Lelampahan "Sidakarya" Topeng Bondres Inovatif Sanggar Seni Nong-Nong Kling minakadi 1) pengetahuan ring lengkara 'ne jani yen iraga suba nawang kone pengetahuan', 2) pertama ring lengkara 'ah pertama malajah', 3) harus ring lengkara 'malajah harus iraga'.

Campuh kode sane pinih akeh kapolihang inggih punika campuh kode sajeroning wangun kruna. Indike punika pateh sakadi tetilikan Rai (2012) sane akeh molihang campuh kode sajeroning wangun kruna. Sajeroning ring Lelampahan "Sidakarya" Topeng Bondres Inovatif Sanggar Seni Nong-Nong Kling, kruna sane ngranjing pinaka campuh kode inggih punika saking basa Indonesia miwah basa Inggris. Kawentenan sane pinih akeh inggih punika kruna saking basa Indonesia sane marupa kruna lingga. Lianan ring punika, taler kakantenang kruna tiron, kruna satma, miwah kruna dwilingga sane ngaranjing pinaka campuh kode sajeroning wangun kruna ring Lelampahan "Sidakarya" Topeng Bondres Inovatif Sanggar Seni Nong-Nong Kling. Kruna sane ngranjing pinka campuh kode wantah kruna-kruna sane lumbrah kaanggen sajeroning mababaosan sarahina, sakadi nomor, pengetahuan miwah pertama.

Yening rerehang ring basa Bali, kruna-kruna punika wenten basa Balinyane utawi prasida kagentosin antuk basa Bali, nanging wenten kruna-kruna basa Indonesia sane arang kagentosin antuk basa Bali. Kruna nomor kagentosin antuk wilangan, pengetahuan kagentosin antuk kaweruhan, pertama kagentosin kapartama, punika kantun sering kaanggen sajeroning bebaosan sarahina. Campuh kode sajeroning wangun kruna akeh kakantenang sajeroning bebaosan riantukan kruna saking basa Indonesia lumbrah kaanggen tur dangan ngranjing sajeroning bebaosan sarahina.

Sajeroning wangun frase, campuh kode sane wenten ring Lelampahan "Sidakarya" Topeng Bondres Inovatif Sanggar Seni Nong-Nong Kling minakadi 1) ilmu pengetahuan ring lengkara 'nawang iraga ilmu pengetahuan keto lantas', 2) orang tua ring lengkara 'ngoyong ngajak orang tua', 3) pemuda semangat ne ring lengkara 'bahhh yang pemuda semangat ne'.

Campuh kode sajeroning wangun frase taler kakantenang ring Lelampahan "Sidakarya" Topeng Bondres Inovatif Sanggar Seni Nong-Nong Kling. Samian frase sane ngaranjing pinaka campuh kode mawit saking basa Indonesia. Sane dados ceciren campuh kode sajeroning wangun frase inggih punika kawangun antuk kalih kruna utawi langkung miwah nenten madaging lingging (Chaer, 2003). Imba campuh kode sajeroning wangun frase sakadi tepuk tangan, dari mana, miwah orang tua.

Frase punika ngranjing riantukan pragina ring Lelampahan "Sidakarya" Topeng Bondres Inovatif Sanggar Seni Nong-Nong Kling waged mabasa Indonesia. Lianan ring punika, frase sane ngranjing pinaka campuh kode sukeh kagentosin antuk basa Bali utawi sukeh ngererehang padanan sane anut ring basa Bali. Campuh kode wangun frase ring Lelampahan "Sidakarya" Topeng Bondres Inovatif Sanggar Seni Nong-Nong Kling kawentenannyane akehan ring wangun kalusa, nanging kidikan ring wangun kruna. Indike punika nyihnayang kruna danganan ngranjing sajeroning bebaosan yening saihang sareng frase.

Samaliha, campuh kode sajeroning wangun klausa sane wenten ring Lelampahan "Sidakarya" Topeng Bondres Inovatif Sanggar Seni Nong-Nong Kling minakadi 1) setengah-setengah tepuk tangan ring lengkara 'Da nake setengahsetengah tepuk tangan', 2) yang penting panca unsur itu sudah ada sudah bisa menuju ring lengkara 'ada 
madan toyam (yeh) yang penting panca unsur itu sudah ada sudah bisa menuju Ida Sang Hyang Widhi', 3) Iuar biasa maknaring lengkara 'satmaka luar biasa makna bungan sandat'

Sane pinih untat inggih punika campuh kode sajeroning wangun klausa. Klausa sane ngranjing pinaka campuh kode inggih punika klausa saking basa Indonesia. Ceciren campuh kode sajeroning wangun klausa inggih punika ngranjingang kosa basa lianan ring basa kaanggen sane marupa angkepan kruna, sane sakirang-kirangnyane kawangun antuk jejering miwah lingging (Baehaqie, 2008).

Lianan ring punika, kalusa taler madue teges wangun lengkara sane marupa angkepan kruna sane madue lingging. Tegesnyane, sajeroning wangun punika madaging kruna utawi frase sane madue kawigunan pinaka lingging (Chaer, 2003). Klausa sane wenten ring Lelampahan "Sidakarya" Topeng Bondres Inovatif Sanggar Seni Nong-Nong Kling wenten sane jangkep miwah sane nenten jangkep (Verhaar, 2006).

Imba kalusa sane kakantenang, sakadi yang paling sulit di dunia ini adalah tinggal di rumah orang lain pinaka klausa jangkep miwah yang namanya kejar pendidikan itu sendri pinaka klausa nenten jangkep. Klausa sane ngaranjing pinaka campuh kode wantah klausa saking basa Indonesia. Indike punika nyihnayang basa Indonesia dahat ngiusin krama Bali sajeroning mabasa Bali.

Saking tigang soroh campuh kode manut ring wangun kerta basannyane, campuh kode sajeroning wangun klausa kawentenannyane pinih akidih riantukan klausa saking basa lian arang ngranjing ring bondres pragina inucap. Indike punika nyihnayang kawagedan pragina sajeroning mabasa.

Nganenin kahanan campuh kode sane kapolihang antuk kramaning saduwicara sane kamargian majeng pragina bondres ring Lelampahan "Sidakarya" Topeng Bondres Inovatif Sanggar Seni Nong-Nong Kling minakadi

(1) Pendidikan, Dadalan campuh kode sane kabahbahang antuk pragina ring Lelampahan "Sidakarya" Topeng Bondres
Inovatif Sanggar Seni Nong-Nong Kling, inggih punika sajeroning pendidikan mangda pamiarsa ngresepang indik napi sane kabaosang. Sang sane madue pendidikan tinggi pastika madue kawagedan sane lewih, sakadi kawagedan mabasa. Puniki wenten salampah laku (riwayat) pendidikan olih Nyoman Suardika, S.Ag.,M.Fil.H. Ipun kuliah jenjang S1 miwah S2 ring Institut Hindu Dharma Negeri (IHDN) Denpasar. Sane mangkin sampun makarya dados dosen filsafat agama hindu ring STAH Negeri Mpu Kuturan Singaraja. Taler ipun dados 'Wayan Punta' sajeroning Lelampahan "Sidakarya" Topeng Bondres Inovatif Sanggar Seni Nong-Nong Kling. Antuk punika sinah sampun yening manut pendidikan pinaka sane ngawinang wenten campuh kode sajeroning Lelampahan "Sidakarya" Topeng Bondres Inovatif Sanggar Seni Nong-Nong Kling. (2) Pergaulan, Maosang indik campuh kode pastika sampun mapaiketan sareng pergaulan, silih tunggilnyane basa sane kaanggen ri kala mabebaosan sareng sawitra miwah sane lianan. Sajeroning pergaulan nenten ja wantah asiki basa pergaulan sane kaanggen, nanging majanten nganggen akeh basa daerah utawi dialek sane kaanggen mangda prasida lengut miwah menarik ri kala masolah. Saking pasawitran (pergaulan) pragina bondres punika kapolihang campuh kode. Sakadi pragina sane mawasta Gede Pasek Sariada, S.Pd.sane sampun makarya dados photografer, sarahina-rahina bergaul ring wewidangan Denpasar. Antuk punika, ipun ngamolihang pikenoh utawi materi sane wenten ring campuh kode. Saking materi punika, wau kabaktayang ring sesolahan topeng bondres sidakarya. Dadosnyane wewidangan (lingkungan) ngawinang wenten campur kode Lelampahan "Sidakarya" Topeng Bondres Inovatif Sanggar Seni Nong-Nong Kling. (3) Teknologi, Maosang teknologi ring aab sakadi mangkin sane sayan nglimbak ngawinang pragina bondres sajeroning Lelampahan "Sidakarya" Topeng Bondres Inovatif Sanggar Seni Nong-Nong Kling ngaryanin inovasi sane kaanggen ri kala masesolahan mangda nenten rered olih 
aab sakadi mangkin miwah mangda prasida ngicen bebanyolan olih para krama utaminyane para yowanane mangda kayun manonton sesolahan. Sesolahannyane daweg dumun wantah nganggen basa bali alus utawi sastrasastra sane kabaosang, nanging ring aab sakadi mangkin taler kaicen antuk nganggen budaya basa lianan sane wenten ring jagat Bali puniki. Antuk punika akeh basa utawi kruna-kruna sane kaanggen ri kala masolah sane kaambil saking panglimbak teknologi. Silih sinunggil kruna sane kaanggen mabebaosan olih pragina sane mawasta I Gede Mas Budayasa, S. Ag., pinaka 'ayu ting-ting' miwah sane mawasta Komang Ajik pinaka 'gede lesung' mangda nganutin aab sane mangkin inggih punika "icang lakar update status malu di facebook".

\section{Implikasi}

Ring tetilikan puniki sampun katlatarang indik soroh, miwah kahanan, indik kawentenan campuh kode ring Lelampahan "Sidakarya" Topeng Bondres Inovatif Sanggar Seni Nong-Nong Kling. Manut saking pikolih lan tetepasan sane sampun kawedar ring tetilikan puniki, prasida kasinahang kawentenan campuh kode ring Lelampahan "Sidakarya" Topeng Bondres Inovatif madue iusan sane becik (dampak positif) miwah iusan sane nenten becik (dampak negatif). Iusan sane becik (dampak positif) saking kawentenan campur kode ring Lelampahan "Sidakarya" Topeng Bondres Inovatif inggih punika sakadi, sane kapertama nincapnyane krama Bali sane seneng nonton Lelampahan "Sidakarya" Topeng Bondres Inovatif, kaping kalih prasida ngawinang dangan para krama Bali nonton Lelampahan "Sidakarya" Topeng Bondres Inovatif ring sajeroning ngresepang suksman Lelampahan "Sidakarya", lan sane kaping untat kawentenan basa Bali prasida sayan kasenenging olih krama Bali majalaran antuk nonton Lelampahan "Sidakarya" Topeng Bondres Inovatif.

Tiosan ring punika kawentenan campuh kode taler madue iusan sane nenten becik (dampak negatif). lusan sane nenten becik (dampak negatif) saking kawentenan campuh kode ring Lelampahan "Sidakarya" Topeng Bondres Inovatif inggih punika sakadi, sane kapertama kirangnyane kayun krama Bali antuk nonton sajeroning Lelampahan "Sidakarya" Topeng Bondres Inovatif, kaping kalih nincapnyane pawigunan campuh kode ring Lelampahan "Sidakarya" Topeng Bondres Inovatif miwah bebaosan krama Bali, lan sane kaping untat kawentenan campuh kode puniki prasida ngawinang krama Bali nenten uning ngawigunayang sor singgih basa Bali sane patut.

\section{PAMUPUT}

Sajeroning ringkesan ring tetilikan puniki pacang kabahbahang indik ringkesan saking Adyaya I kantos Adyaya IV. Indike punika pacang kabahbahang ring sor.

Sajeroning Adyaya I inggih punika ngenenin indik Purwaka mahbahang indik dadalan pikobet, ngrereh pikobet, ngwatesin pikobet, bantang pikobet, tetujon tetilikan, kawigunan tetilikan ring Lelampahan "Sidakarya" Topeng Bondres Inovatif Sanggar Seni Nong-Nong Kling. Nglantur ring Adyaya II ngenenin indik Sepat Siku-Siku mahbahang indik Sosiolinguistik, Kedwibahasaan, Bondres, lan Tetilikan asoroh sane kanggen sajeroning tetilikan puniki. Adyaya III inggih punika ngenenin indik Kramaning Tetilikan mahbahang indik palihan tetilikan, jejering miwah pandangan tetilikan, parikrama mupulang data, piranti tetilikan, lan data tureksa. Sajeroning Adyaya IV inggih punika ngenenin indik Pikolih lan Tetepasan mahbahang indik soroh campuh kode manut pawiwit basa, soroh campuh kode manut wangun kruna, lan pawesana sane ngawinang campuh kode ring Lelampahan "Sidakarya" Topeng Bondres Inovatif Sanggar Seni Nong-Nong Kling saha implikasi sajeroning tetilikan puniki.

Saking pikolih miwah tetepasan sane sampun katelatarang ring ajang, prasida katingkesang sakadi (1) Soroh campuh kode ring Lelampahan "Sidakarya" Topeng Bondres Inovatif Sanggar Seni Nong-Nong Kling manut 
pawiwit basa sane kaambil marupa 220 data campuh kode ka tengah, 12 data campuh kode ka sisi miwah 1 data campuh kode cecampuhan. Manut wangun kerta basannyane, soroh campuh kode sane wenten ring Lelampahan "Sidakarya" Topeng Bondres Inovatif Sanggar Seni Nong-Nong Kling marupa 115 data campuh kode sajeroning wangun kruna, 58 data campuh kode sajeroning wangun frase, miwah 32 data campuh kode sajeroning wangun klausa. (2) Dadalan campuh kode ring Lelampahan "Sidakarya" Topeng Bondres Inovatif Sanggar Seni Nong-Nong Kling wenten saking pariindikan pamaos miwah saking pariindikan basa. Saking pariindikan pamaos, dadalan campuh kode sane wenten ring Lelampahan "Sidakarya" Topeng Bondres Inovatif Sanggar Seni Nong-Nong Kling inggih punika mangda pamiarsa dangan ngresepang pariindikan sane kabaosang miwah nenten samian krama Bali waged mabasa Bali. Samaliha, saking pariindikan basa, sane dados dadalan campuh kode ring Lelampahan "Sidakarya" Topeng Bondres Inovatif Sanggar Seni Nong-Nong Kling, minakadi campuh kode kanggen ngamedalang bebanyolan.

Malarapan antuk pikolih sane sampun kabahbahang ring ajeng, sane mangkin wenten piteket-piteket sane jagi kabahbahang sakadi (1) Majeng ring seniman utawi pragina bondres mangda nguratiang basa sane kaanggen sajeroning ngelampahang bondres. Indike puniki mabuat pisan ritatkala seniman utawi para pragina bondres ngajegang kawentenan basa Bali, riantukan asapunika, seniman utawi pragina bondres punika wantah silih tunggil pilar sane mersidayang basa Bali miwah budaya ajeg. (2) Majeng ring panilik sane lianan, mangda prasida nglimbakang tetilikan puniki. Panglimbak sane kaaptiang inggih punika mangda nglaksanayang tetilikan sane asoroh, silih sinunggilnyane ngeninin indik alih kode sajeroning ring Lelampahan "Sidakarya" Topeng Bondres Inovatif Sanggar Seni Nong-Nong Kling. Indike punika kaaptiang kalaksanayang mangda tetilikan salanturnyane prasida maripurnyang tetilikan puniki. (3) Majeng ring para panonton Lelampahan "Sidakarya" Topeng Bondres Inovatif Sanggar Seni Nong-Nong Kling, kaptiang mangda prasida nguningin kawingunan lan suksman saking kawentenan campuh kode ring Lelampahan "Sidakarya" Topeng Bondres Inovatif Sanggar Seni Nong-Nong Kling, mangda para panonton Lelampahan "Sidakarya" Topeng Bondres Inovatif Sanggar Seni Nong-Nong Kling nenten iwang ring sajeroning ngawigunayang parindikan campuh kode.

\section{KAPUSTAKAAN}

Arikunto, Suharsimi. 2006. Metode Penelitian: Suatu Pendidikan Praktek. Jakarta: PT Rineka Cipta.

Baehaqie, Imam. 2008. Sintaksis Teori dan Analisis. Yogyakarta: Pustaka Pelajar.

Bandem, I Made. 1983. Perkembangan Topeng Bali sebagai Seni Pertunjukkan. Denpasar: Pemerintah Daerah Tingkat I Bali.

Bandem lan Rembang, 1976. Perkembangan Topeng Bali Sebagai Seni Pertunjukan.Denpasar: Proyek Penggalian, Pembinaan, Seni Klasik/Tradisional Dan Kesenian Baru Pemerintah Daerah Tingkat I Bali.

Chaer, Abdul. 2003. Linguistik Umum. Jakarta: PT Rineka Cipta.

Jendra, Wayan. 1991. Dasar-dasar Sosiolinguistik. Denpasar: Ikayana

Kardji, I Wayan. 2007. Topeng Prembon dan Mantra Sang Penari. Denpasar: Panakom Publishing.

Kodi, I Ketut. 2006. Tapel Bondres dalam Perubahan Masyarakat Bali: Suatu Kajian Budaya. Tesis (Nenten Kamijilang). Program Studi Kajian Budaya, UNUD.

Koentjaraninggrat. 1967. Bebarapa Pokok Antropologi Sosial. Jakarta: Dian Rakyat

Mahsun. 2010. Genolinguistik. Yogyakarta: Pustaka Pelajar.

Nababan, P.W.J. 1991. Sosiolinguistik: Suatu Pengantar. Jakarta: PT Gramedia Pustaka Utama. 
Rai, Ida bagus. 2012. Analisis Campur Kode pada Perkuliahan Berbicara Bahasa Bali di Jurusan Pendidikan Bahasa Bali D3 UNDIKSHA. Tesis (Nenten Kamijilang). Program Studi Pendidikan Bahasa, UNDIKSHA.

Suhardi, Basuki. 2009. Pedoman Penelitian Sosiolinguistik. Jakarta: Pusat Bahasa Departemen Pendidikan Nasional.

Sukardi. 2003. Metodologi Penelitian Pendidikan: Kompetensi dan
Praktiknya. Yogyakarata: Bumi Aksara.

Verhaar, J.W.M. 2006. Asas-asas Linguistik Umum. Yogyakarta: Gadjah Mada University Press.

Wendra, I Wayan. 2011. Buku Ajar Penulisan Karya Ilmiah. Singaraja: UNDIKSHA

Yudabakti, I Mada miwah I Wayan Watra. 2007. Filsafat Seni Sakral. Surabaya:Paramit. 